\title{
Foresight from the impacts of COVID-19 on air pollution
}

\author{
Silvia Machado' ${ }^{1}$ Samina Mehnaz ${ }^{2}$
}

Published online: 31 August 2020

(c) Society for Environmental Sustainability 2020

Mankind is currently experiencing unprecedented situations, with immeasurable uncertainties, that have put the world to an endurance test and led to unpredicted environmental impacts. The COVID-19 outbreak, reportedly started in December 2019, in the city of Wuhan, Hubei province, in China, led the world to lockdowns and industrial shutdowns as well as restricted travelling (El Zowalaty et al. 2020). The pandemic interacts, directly and indirectly, with many of earth systems and sciences. Although very disruptive to society and socially painful, it has also provided unparalleled opportunities for scientific development and actions.

Increase in use of fossil fuels and related emissions from power generation, traffic combustion, and industrial activities, led to the upsurge of pollution related cardiovascular and respiratory diseases (Lelieveld et al. 2019), such as ischemic heart disease (40\%), stroke (40\%), chronic obstructive pulmonary disease (COPD; $11 \%)$, lung cancer (6\%), and acute lower respiratory infections in children (3\%) (WHO 2016). The reaction to air pollutants varies, depending on factors such as type of pollutant, the degree of exposure, individual health status and genetics (Vallero 2008).

Air pollution, both indoor and outdoor, is considered the leading risk factor for human mortality, contributing six percent globally, with 3.4-4.2 million premature deaths every year (Ritchie and Roser 2019; Silva et al. 2013; World Bank and Institute for Health Metrics and Evaluation 2016). In low to middle income countries, particularly in the Middle East and North Africa, it can account for 10 percent or higher death rate. Egypt reported highest death rate in 2017, with 114 deaths per 100 thousand individuals, ascribed to outdoor air pollution. This death rate is 10 times higher than Sweden, Finland and New Zealand. Following

Silvia Machado

silviamachado@fccollege.edu.pk

1 Department of Environmental Sciences, Forman Christian College (A Chartered University), Lahore 54600, Pakistan

2 School of Life Sciences, Forman Christian College (A Chartered University), Lahore 54600, Pakistan
Egypt, several other countries in the Asian continent including China, India, Pakistan and Bangladesh, reported a high mortality rate due to air pollution.

The death distribution patterns can be linked to low to middle income, densely populated regions, undergoing a change through industrialization (Ritchie and Roser 2019). In higher income countries the number of deaths related with air pollution are lower as the pollution levels have come down, and overall health situation and facilities are better.

The World Bank and Institute for Health Metrics and Evaluation (2016), in a joint study on the economic effects of pollution-related fatalities, estimated that every tenth death is associated with air pollution. This translates in productivity losses and life quality degradation associated with air pollution, with an approximate cost of US \$5 trillion per year, where, US \$225 billion are lost in labor income. These values correspond to the combined Gross Domestic Product (GDP) of Canada, Mexico and India. These fatalities are particularly harmful for developing countries. When assessed at the country level, this report refers to pollution related deaths in China on top of the economic losses, with 10 percent of the GDP, followed by India with 7.69 percent loss; Sri Lanka and Cambodia, each lost approximately 8 percent, in 2013.

The emissions related with fossil fuels are estimated to contribute $65 \%$ of the excess mortality rate due to air pollution, and $70 \%$ of the climate cooling by aerosols attributable to human emissions (Lelieveld et al. 2019). Particulate Matter (PM) and tropospheric ozone are two local outdoor air pollutants with potential health impacts on the population, particularly PM, with higher impact than ozone. Between 91 and 95 percent of the world's population is exposed to higher than $10 \mu \mathrm{g} / \mathrm{m}^{3} \mathrm{PM}$, exceeding the WHO recommended limit (WHO 2006, 2016; Ritchie and Roser 2019).

The COVID-19 pandemic resulted in restricted human activities throughout the world since March 11, 2020. The measures taken to decease the spread of the virus such as strict traffic rules, intense quarantine, closure of airports, cancelation of social events, social distancing, closure of all the zones which were the sources for higher cases 
of SARS- CoV-2, and closure of highways and railways provided the opportunity to determine the effectiveness of restricted anthropogenic activities on the air quality (Chang et al. 2020). The cost of 'air pollution control measures' plays a vital role in the development of policies to reduce emissions. COVID-19 provided the proof of effectiveness of control measures to reduce emissions, to the policy makers.

Major cities (where the air pollution is of major concern), were studied to compare the concentrations of some of the criteria pollutants before the outbreak of disease and during the full or partial lockdowns. In Rio de Janeiro, Brazil, the concentrations of major pollutants varied significantly when pre-virus outbreak and lockdown conditions were compared. Carbon monoxide (CO) levels showed the most substantial reductions which are related to light vehicular emissions. Nitrogen dioxide $\left(\mathrm{NO}_{2}\right)$ and particulate matter also showed reductions (Dantas et al. 2020).

A study conducted by Mahato and Pal (2020) in Delhi, India, claimed that after forced restrictions on outdoor activities, the air pollution levels dropped rapidly which sparked the discussions of lockdown being an effective solution to control air pollution. The data on air quality was gathered for seven major criteria of air pollutants, namely particulate matter $\left(\mathrm{PM}_{10}\right.$ and $\left.\mathrm{PM}_{2.5}\right), \mathrm{NO}_{2}$, sulfur oxide, $\mathrm{CO}$, ozone and ammonia for 34 stations distributed throughout the city. The city air quality spatial pattern, during the lockdown situation, showed remarkable improvement. Among all other pollutants, the $\mathrm{PM}_{10}$ and $\mathrm{PM}_{2.5}$ concentrations showed maximum reduction by up to $50 \%$. While the pre COVID-19 phase showed high concentrations of both. The concentrations of $\mathrm{NO}_{2}$ and $\mathrm{CO}$ levels in the outdoor air also reduced during the lockdown phase. Along with the reductions in concentrations of pollutants, $40-50 \%$ improvement in air quality resulted in just 4 days after the implementation of lockdown. Improvements were seen in all parts of the city.

Another study by Sharma et al. (2020) dealt with six criteria air pollutants, particulate matter, $\mathrm{NO}_{2}$, ozone, sulfur oxide, and CO, during March 16 to April 14 from years 2017 to 2020, in the 22 cities from different parts of India. Decrease in the concentrations of the selected pollutants was observed during the lockdown period when compared to concentrations from previous years. The air quality index (AQI) reduced in all areas of the country. The risk associated with PM reduced by 52 percent nationwide due to controlled human activity. Mandal and Pal (2020) determined the impact of lockdown conditions on environmental aspects, and reported that concentration levels of $\mathrm{PM}_{10}$ declined significantly, just after 18 days of lockdown implementation. Several studies determined that, even during unfavorable meteorological conditions, significant improvements in air quality can be seen with strict implementation of air quality controls.
In addition, another study from China, evaluated the impacts of COVID-19 outbreak on the environment. The outcomes of the study depict the improvement in air quality in a very short time span and reduction in carbon emission. Furthermore, COVID-19 lockdowns have resulted in reduced concentration of $\mathrm{NO}_{2}$ in the atmosphere throughout the country (Wang and Su 2020). The results are useful insight for the regulatory agencies proving that controlling pollution at source can enhance air quality. Study further claims that temporary source control can restore environment quality.

The major reduction of emissions was related with traffic induced air pollution. Considering the pre-lockdowns and lockdown periods, the $\mathrm{PM}_{2.5}$ concentrations were analyzed for ten US states and in the District of Columbia. It was found that the concentrations of $\mathrm{PM}_{2.5}$ decreased on an average of 12.8 percent in seven states and in the capital. This study links the decrease in air pollution with the 483 causespecific deaths, in the urban areas (Son et al. 2020). When compared with the national reality, it affirms the reduction of concentrations of $\mathrm{PM}_{2.5}$ in urban centers and areas that established earlier lockdowns. The $\mathrm{NO}_{2}$ concentration showed a significant decline of $25 \%$, during the mitigation measures, when compared with previous years (Berman et al. 2020).

The COVID-19 pandemic created challenges to human activities, economies and health care systems around the world. It emphasized the inequalities existing in the world at different levels. Human activities leading to pollution may have intensified the pandemic, considering the resulting underlying health conditions of the population, result of the previous environmental degradation, and the burden put on the health care systems. However, the lockdowns, industrial shutdowns, quarantines, closing borders and overall reduced mobility of the population (for tourism and/or work commutes) led to air pollution reduction. These positive effects on the environment are mostly likely to be temporary but may shed a light on how changes in the human behavior may prompt positive effects (Lelieveld et al. 2019; Hassan et al. 2020).

The mitigation measures established to reduce the COVID-19 transmission resulted in an air quality improvement, which is expected to influence the mortality rate associated with outdoor air pollution. Recent studies are significant to show the potential health benefits that can result from air pollution reduction and implementation of stringent and futuristic policies. Specific actions and solutions need to be taken in order to reduce environmental damage in the atmosphere (due to anthropogenic activities), and to ensure the benefits that be sustainable. Measures such as work from home, reducing travel, and teleconferencing, may have a significant positive impact on the air quality by contributing to the decrease of fossil fuel related emissions, 
and other anthropogenic sources. A bigger focus, through investment and research, needs to be put in biofuels, considering these are one of the largest sources of renewal energy. A more sustainable and long-term solution needs to include new technologies to reduce the dependency on fossil fuels for transport and energy, considering that the decrease of emissions in these two major areas has shown to have major impacts on reduction in air pollution. This will overall have a long term and sustainable impact on environment leading to better conditions not only for humans but for the whole ecobiome known as Earth.

\section{References}

Berman JD, Ebisu K (2020) Changes in US air pollution during the COVID-19 pandemic. Sci Tot Environ 739:139864. https://doi. org/10.1016/j.scitotenv.2020.139864

Chang SL, Harding N, Zachreson C, Clif OM, Prokopenko M (2020) Modelling transmission and control of the COVID-19 pandemic in Australia. arXiv 2:10218

Dantas G, Siciliano B, Franca BB, da Silva CM, Arbilla G (2020) The impact of COVID-19 partial lockdown on the air quality of the city of Rio de Janeiro. Brazil Sci Total Environ 729:139085. https ://doi.org/10.1016/j.scitotenv.2020.139085

El Zowalaty ME, Young SG, Järhult JD (2020) Environmental impact of the COVID-19 pandemic - a lesson for the future Taylor and Francis; 2020. Infect Ecol Epidemiol 10:1-1768023. https://doi. org/10.1080/20008686.2020.1768023

Hassan MM, El Zowalaty ME, Khan SA, Islam A, Nayem MRK, Järhult JD (2020) Role of environmental temperature on the attack rate and case fatality rate of Coronavirus Disease 2019 (COVID19) Pandemic. Infect Ecol Epidemiol 10(1):1792620. https://doi. org/10.1080/20008686.2020.1792620

Lelieveld J, Klingmüller K, Pozzer A, Burnett RT, Haines A, Ramanathan V (2019) Effects of fossil fuel and total anthropogenic emission removal on public health and climate. PNAS USA 116(15):7192-7197. https://doi.org/10.1073/pnas.1819989116
Mahato S, Pal S, Ghosh KG (2020) Effect of lockdown amid COVID19 pandemic on air quality of the megacity Delhi. India Sci Tot Environ. https://doi.org/10.1016/j.scitotenv.2020.139086

Mandal I, Pal S (2020) COVID-19 pandemic persuaded lockdown effects on environment over stone quarrying and crushing areas. Sci Tot Environ. https://doi.org/10.1016/j.scitotenv.2020.139281

Ritchie H, Roser M (2019) - "Air Pollution". Published online at OurWorldInData.org. Available online https://ourworldindata.org/ air-pollution. Accessed 26 July 2020

Sharma S, Zhang M, Gao J, Zhang H, Kota SH (2020) Effect of restricted emissions during COVID-19 on air quality in India. Sci Tot Environ 728:38878. https://doi.org/10.1016/j.scito tenv.2020.139087

Silva RA, West JJ, Zhang Y, Anenberg SC et al (2013) Global premature mortality due to anthropogenic outdoor air pollution and the contribution of past climate change. Environ Res Lett 8(3):034005. https://doi.org/10.1088/1748-9326/8/3/034005

Son J-Y, Fong KC, Heo S, Kim H, Lim CC, Bell ML (2020) Reductions in mortality resulting from reduced air pollution levels due to COVID-19 mitigation measures. Sci Tot Environ 744:141012. https://doi.org/10.1016/j.scitotenv.2020.141012

Vallero DA (2008) Fundamentals of Air Pollution, 4th edn. Elsevier Academic Press, London

Wang Q, Su M (2020) A preliminary assessment of the impact of COVID-19 on environment - a case study of China. Sci Tot Environ 1:38915. https://doi.org/10.1016/j.scitotenv.2020.138915

World Bank, Institute for Health Metrics and Evaluation (2016). The cost of air pollution : Strengthening the economic case for action. World Bank, Washington, DC. World Bank. Available online https ://openknowledge.worldbank.org/handle/10986/25013. Accessed 23 July 2020

World Health Organization (2006). WHO Air quality guidelines for particulate matter, ozone, nitrogen dioxide and sulfur dioxide: global update 2005: summary of risk assessment (No. WHO/SDE/ PHE/OEH/06.02). Geneva: World Health Organization.

World Health Organization (2016) Ambient Air Pollution: a global assessment of exposure and burden of disease. WHO, Geneva

Publisher's Note Springer Nature remains neutral with regard to jurisdictional claims in published maps and institutional affiliations. 